\title{
EYE AND SKIN CHANGES IN PSYCHIATRIC PATIENTS TREATED WITH CHLORPROMAZINE* $\dagger$
}

\author{
BY
}

\author{
M. B. R. MATHALONE \\ From the Department of Experimental Ophthalmology, Institute of Ophthalmology. \\ University of London
}

OCULAR effects in patients treated with a phenothiazine derivative were first described by Verrey (1956) and also by Kinross-Wright (1956); these authors found pigmentary retinal changes, and the compound in question (NP.207) was never marketed. The formula of this and related compounds is shown in Fig. 1. May, Selymes, Weekley, and Potts (1960) described pigmentary retinal changes in patients receiving large doses of thioridazine (Melleril), which differs only from NP.207 in having a methylthio group instead of a chlorine atom.

Chlorpromazine (Largactil) (Fig. 1), introduced in 1953, has been widely used in general medicine and in psychiatry, especially in the longterm intensive treatment of chronic schizophrenic patients, and several ocular effects caused by its use have been reported. Oculogyric crises have occasionally been observed as a part of the Parkinsonian syndrome which is sometimes produced (Ayd, 1961). Blurred vision, due to an atropine-like action causing a temporary paralysis of accommodation, has been reported (Sinha and Mitra, 1955; Giacobini and Lassenius, 1954). Jonas (1959) reported a chlorpromazineinduced miosis.

Cloud, Hakim, and Griffin (1961), reporting intra-ocular damage in animals caused by methoxalan, a photosensitizing agent which is a

Methoxalon

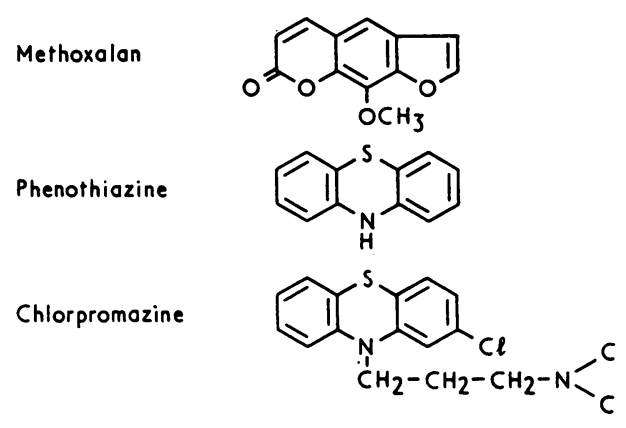

Thioridazine (Melleril)<smiles>CCN1c2ccccc2Sc2ccc(SC)cc21</smiles>

N.P. 207 phenothiazine derivative, suggested that chlorpromazine was potentially capable of causing similar damage. This led Bock and Swain (1963) to investigate nineteen patients under 55 years of age who had received at least $200 \mathrm{mg}$. chlorpromazine daily. They observed two cases of raised intra-ocular pressure and queried its significance. They reported no corneal or lens changes attributable to the drug, although they did mention that one 50 -year-old patient had "powdery white spots" on the anterior capsule in the central pupillary area.

* Received for publication September 1, 1965

† Address for reprints: Moorfields Eye Hospital, City Rd, London, E.C.1. 
It is only since the report of Greiner and Berry (1964) that the long-term effects of chlorpromazine therapy on the eye have been appreciated; they noticed a peculiar pigmentation of the skin in seventy patients, all women, out of many thousands who had been receiving large doses of chlorpromazine, averaging 500 to $1,500 \mathrm{mg}$. daily. This skin pigmentation was very marked in 21 patients and twelve of these were found to have visible corneal and lens opacities.

Since then several reports of ocular changes have been published, mainly from North America, where the drug has been given in larger doses than in Great Britain (Feldman and Frierson, 1964; Zelickson and Zeller, 1964; Greiner, Nicolson, and Baker, 1964; deLong, Poley, and McFarlane, 1965; Wetterholm, Snow, and Winter, 1965; Barsa, Newton, and Saunders, 1965; Ban and Lehmann, 1965). The only British reports are those of Cairns, Capoore, and Gregory (1965) and Mathalone (1965).

\section{Skin Pigmentation}

In normal skin melanin is found in the epidermis, and becomes more evident in light-skinned subjects on exposure to sunlight. Phenothiazine derivatives are known to cause dermatological conditions which include contact sensitivity, generalized eruption, and photosensitivity; the latter can occur after brief exposure to sunlight. The skin pigmentation of chlorpromazine-treated patients reported by Greiner and Berry and other workers ranged in intensity from a violaceous hue through a metallic slate-grey colour to black discoloration, as seen in some patients in North America who had received very large doses for long periods. This pigmentation is restricted to exposed areas of the body, chiefly the face, neck, and hands. Skin biopsies on these patients have usually shown pigment in the superficial areas of the dermis in perivascular macrophages, whereas in photosensitized patients the pigment is said to be in the epidermis.

In view of these reports of skin and eye changes a clinical survey of patients treated with chlorpromazine was undertaken in England, and 462 patients in seven mental hospitals were examined for changes in the eyes and skin. Most of these patients had been on long-term chlorpromazine therapy; the remainder, serving as controls, had received either other forms of treatment or none. Since lens changes reported in the patients taking chlorpromazine are characteristic and quite different from senile changes, it was not thought necessary to exclude patients in the older age groups.

\section{Method of Investigation}

After an examination of their treatment records, the 462 patients (316 male and 146 female) were classified into four groups:

I. Patients who had received $300 \mathrm{mg}$. chlorpromazine or more daily for 2 years or longer.

II. Patients who had received less than $300 \mathrm{mg}$. daily for 2 years or longer.

III. Patients who had received the drug in any dosage for one year or less.

IV. Schizophrenic patients serving as controls, who had not received chlorpromazine. They were receiving either no drugs or other phenothiazine derivatives and/or other psycho-corrective compounds.

Ocular investigation consisted of an external examination for pigmentation of skin, conjunctiva, or sclera, measurement of pupil size and reaction, and examination of the cornea, lens, and vitreous, using a Gambs 1000 slit lamp. If any abnormality was detected, 
visual acuity and accommodation were estimated, if possible, and the fundus was examined after dilatation of the pupil. Measurement of the ocular tension using a weighted tonometer was made in some cases, and gonioscopy was performed in a few of the more severelyaffected patients. Electro-oculography (EOG) was carried out on cases selected at random. EOG, visual fields, and dark-adaptation tests were carried out on patients showing pigmentation of the retina if they were sufficiently co-operative.

Catecholamines were estimated in the urine of patients selected at random in view of the work of Scott and Nading (1961), which suggested that a pituitary influence might be involved. Several phenothiazine derivatives are known to release melanocyte-stimulating hormone (MSH) from the pituitary in animals. It is possible that an altered excretion of catecholamines resulting from the effect of chlorpromazine on the adrenal hormones may stimulate increased MSH production from the pituitary gland leading to increased pigmentation.

Routine liver function tests were performed in a number of cases in each centre.

\section{Results}

Pigmentation.-There was evidence of photosensitization in exposed areas of skin in many patients, the degree of pigmentation depending upon the extent of exposure to sunlight and varying from patient to patient.

Three patients showed pigmentation of a different type, viz. a slate-grey coloration of the exposed parts of the face, neck, and hands. This was quite obvious, although not as marked as in some of the illustrations of North American patients on high dosages of chlorpromazine. Although this pigmentation and that due to photosensitivity involve the same areas they are not necessarily related. Exposure to sunlight probably played little part in the development of the pigmentation in the most severely-affected patient because he had an indoor occupation and was seen in early spring.

Histopathological studies on skin biopsies using differential staining techniques suggest that this pigment is melanin, but it has not yet been identified; it might be a lipofuscin or a melanin/diagonal chlorpromazine complex. The metabolism of chlorpromazine in man has not been completely elucidated and it is possible that the formation of this dermal pigment involves one or more of its metabolites. Several theories have been advanced to explain the mechanism involved (Greiner and others, 1964; Ban and Lehmann, 1965). All three patients with the slate-grey pigmentation had corneal and lens changes. A more detailed report of the skin changes is in preparation.

Approximately 10 per cent. of patients showed some conjunctival pigmentation, but the significance of this is doubtful as many normal people show patches of similar pigmentation. No scleral pigmentation was seen.

Visual Acuity.-In all patients with no other obvious cause for poor vision this could be corrected to $6 / 9$ or better. Accommodation was normal in those cases in which it was tested.

Pupils.-No significant effect on the pupils was noticed in this series. Among patients in similar age groups examined in similar lighting conditions some had large pupils (7-8 mm.) and a few had small pupils $(2 \cdot 5-3 \mathrm{~mm}$.). However, these patients 
did not appear to have any defect in accommodation and their pupils reacted briskly.

In two patients not already receiving chlorpromazine the drug was given by intramuscular injection in doses of 25 and $50 \mathrm{mg}$. respectively. No change in pupil size or reaction was noticed during the first hour after the injection.

Corneal Changes.- These were seen only in patients showing lens changes (Table I). They consisted of white or yellowish-white deposits situated mainly centrally in the palpebral fissure and at the level of the endothelium and sometimes encroaching into the adjoining posterior stroma (Figs 2 and 3, colour plate, overleaf). Only in one severely-affected case was a major part of the stromal substance involved. These findings correspond closely to those reported by deLong (1965).

TABLE I

INCIDENCE OF OCular Changes

\begin{tabular}{|c|c|c|c|c|c|c|}
\hline \multirow{2}{*}{ Group } & \multirow{2}{*}{ Sex } & \multirow{2}{*}{$\begin{array}{l}\text { No. of } \\
\text { Patients }\end{array}$} & \multicolumn{2}{|c|}{ Cornea } & \multicolumn{2}{|c|}{ Lens } \\
\hline & & & No. & Per cent. & No. & Per cent. \\
\hline \multirow[t]{2}{*}{ I } & $\begin{array}{c}\text { Male } \\
\text { Female }\end{array}$ & $\begin{array}{r}174 \\
97\end{array}$ & $\begin{array}{l}22 \\
24\end{array}$ & $\begin{array}{l}13 \\
25\end{array}$ & $\begin{array}{l}59 \\
39\end{array}$ & $\begin{array}{l}34 \\
40\end{array}$ \\
\hline & Total & 271 & 46 & 17 & 98 & 36 \\
\hline \multirow[t]{2}{*}{ II } & $\begin{array}{c}\text { Male } \\
\text { Female }\end{array}$ & $\begin{array}{l}73 \\
33\end{array}$ & $\begin{array}{l}3 \\
1\end{array}$ & $\begin{array}{l}4 \\
3\end{array}$ & $\begin{array}{r}11 \\
4\end{array}$ & $\begin{array}{l}15 \\
12\end{array}$ \\
\hline & Total & 106 & 4 & 4 & 15 & 14 \\
\hline \multirow[t]{2}{*}{ III } & $\begin{array}{c}\text { Male } \\
\text { Female }\end{array}$ & $\begin{array}{l}25 \\
13\end{array}$ & - & - & 1 & $\begin{array}{r}4 \\
-\end{array}$ \\
\hline & Total & 38 & - & - & 1 & 3 \\
\hline \multirow[t]{2}{*}{ IV } & $\begin{array}{c}\text { Male } \\
\text { Female }\end{array}$ & $\begin{array}{r}44 \\
3\end{array}$ & - & - & - & - \\
\hline & Total & 47 & - & - & - & - \\
\hline
\end{tabular}

Lens Changes.-The incidence is shown in Table I.

They consisted of granular deposits occurring bilaterally and centrally. The majority of affected patients had lesions more or less circular in the pupillary aperture with one or more spikes or projections. These granules could only really be seen using the slit lamp. In some more severely affected patients a star-shaped lesion could be seen. The granules were larger and more discrete than in the less severely affected patients, and sometimes the stellate patterns seemed to be superimposed over the circular lesion. These could be seen ophthalmoscopically (Figs 4, 5, and 6, colour plate, overleaf; and Fig. 7, overleaf, p. 90).

All lesions were situated at the level of the anterior capsule and adjoining subcapsular areas. In some cases granules were seen in the lens substance behind the superficial layer; they were yellowish-white in appearance, a few being golden or brown.

Two patients under the age of 55 years also had anterior cortical cataract, but it is not known if this was related to chlorpromazine. 

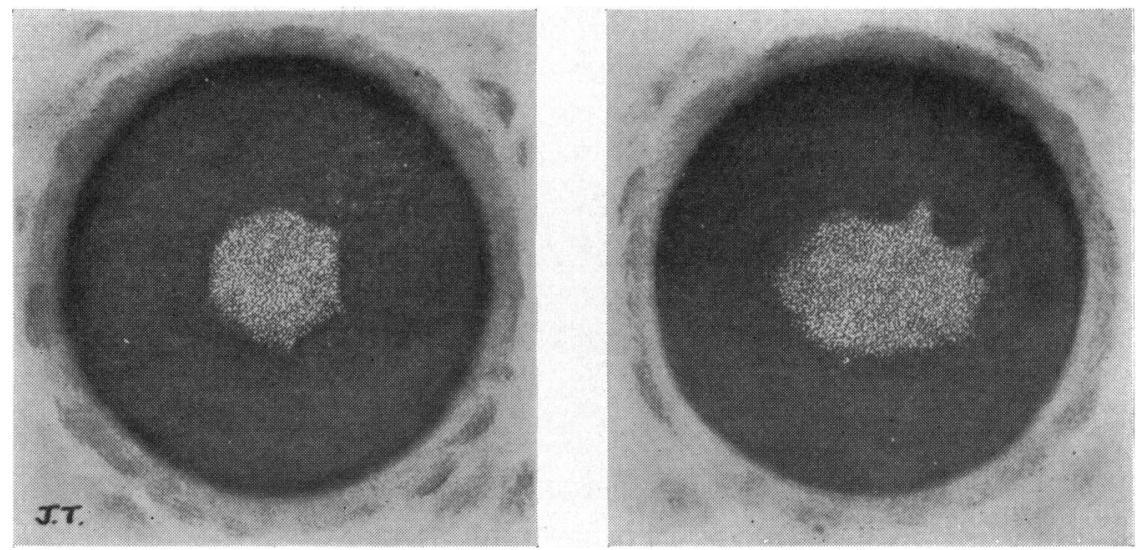

FIG. 7.-Artist's drawings of lens changes in an early case showing a more rounded shape with spikes.

Fundus. - In a series of interesting experiments in which [35s] chlorpromazine and [35 $]$ prochlorperazine were injected into rabbits and hamsters, Potts (1962a, b) found that the radioactive material concentrated in uveal tissue. Whereas, in the rabbit uvea, chlorpromazine was concentrated to a greater extent than prochlorperazine, this difference was reversed in the hamster. In the case of prochlorperazine, the rabbit ciliary body showed a higher concentration than the lens; the reverse was again found with chlorpromazine. Potts suggested that these differences must be based on compound specificity. Since the nature and extent of deposition in these tissues vary from one phenothiazine derivative to another, it is possible that eye changes in man are more likely to occur with certain compounds. Potts (1962a) also found that albino rabbits did not show the uveal concentration phenomenon.

Choroido-retinopathy in man has been reported by only one author (Siddall, 1965 ) in a few cases on very large doses of chlorpromazine. He stated the critical dose to be $2,400 \mathrm{mg}$./day for 24 months, preceded by other smaller doses.

In the present series, two patients showed abnormal retinal pigment.

(1) A schizophrenic man aged 53 showed no effect on the visual function. His visual acuity was $6 / 9$ in the right eye and 6/6 in the left unaided. Peripheral fields and dark-adaptation tests were normal. The EOG showed $\frac{\text { LIGHT RISE }}{\text { DARK TROUGH }} \times 100=225$, i.e. within normal limits. The disc and retinal vessels appeared normal.

(2) A schizophrenic woman aged 58 had been receiving large doses of thioridazine (Melleril) a year previously. The maximum dosage was $1,200 \mathrm{mg}$. daily and the drug had been used for over one year. She had also received large doses of several other phenothiazines. Her corrected visual acuity was $6 / 12$ in the right eye and 6/24 in the left with a pinhole. The EOG was flat. She would not co-operate sufficiently to enable peripheral fields and dark-adaptation tests to be done. The fundus showed a normal-looking disc and vessels, but areas of pigmentation and depigmentation were present. These appearances are very similar to those described by de Margerie (1962) (Fig. 8, colour plate, opposite).

In thirteen cases taken at random an EOG was done (Table II, p. 91).

Although some of these values are low, they are probably all within the lower limit of normal, but for an accurate statistical evaluation a much larger series is required. These patients have been taken off chlorpromazine and the test will be repeated after a year. 


\section{EYE CHANGES DUE TO CHLORPROMAZINE}

2
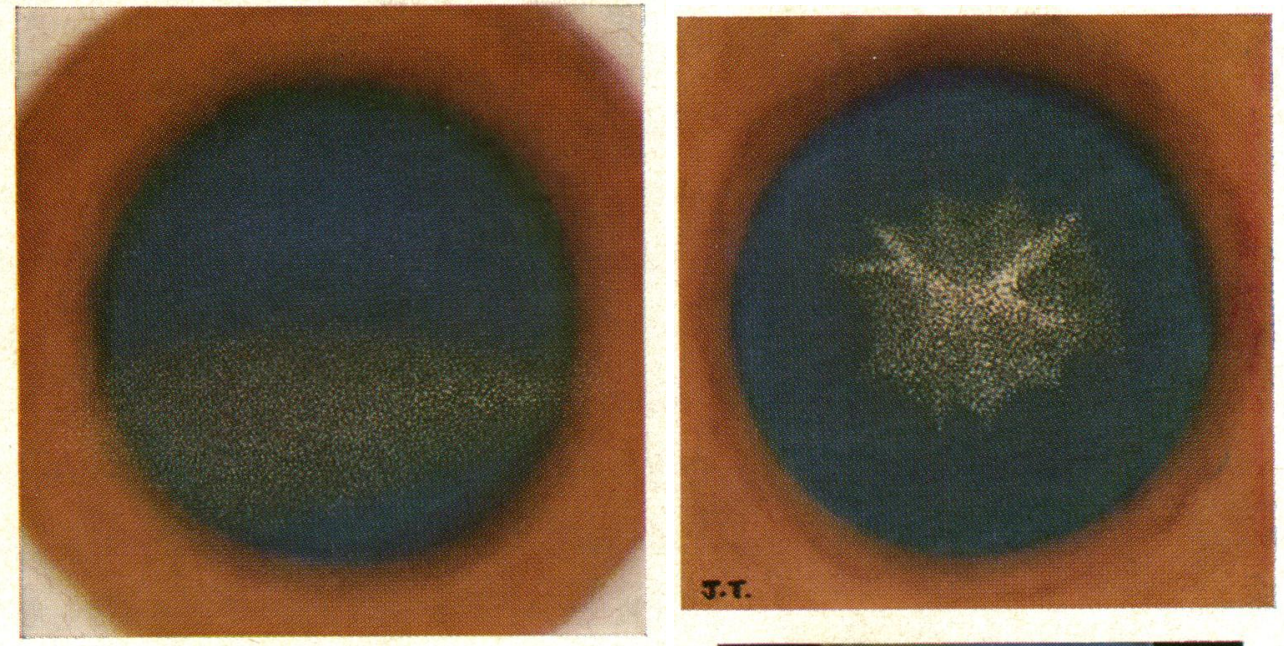

3
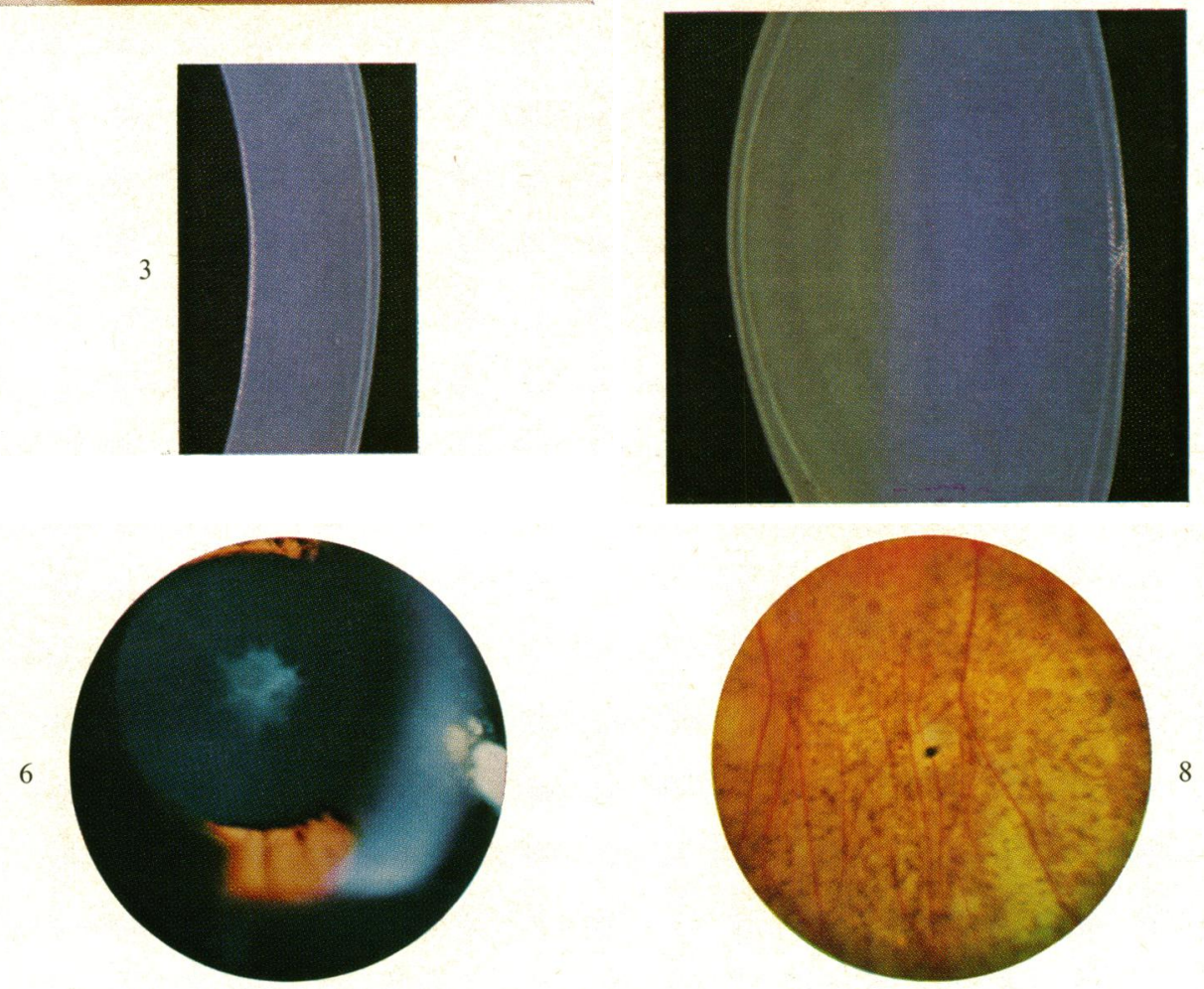

Figs 2 and 3.-Artist's drawings showing corneal changes in a severe case.

FIGS 4 and 5.-Artist's drawings showing lens changes in a severe case.

Fıg. 6.-Slit-lamp photograph of lens changes.

FIG. 8.-Fundus photograph of a patient receiving thioridazine (Melleril).

To face page 90. 
TABLE II

\begin{tabular}{c||c|c}
\hline $\begin{array}{c}\text { Case } \\
\text { No. }\end{array}$ & $\begin{array}{c}\text { Total Dose } \\
(\mathrm{g} .)\end{array}$ & EOG $=\frac{\text { LIGHT PEAK }}{\text { DARK TROUGH }} \times 100$ \\
\hline 1 & 400 & 180 \\
2 & 350 & 160 \\
3 & 480 & 186 \\
4 & 700 & 200 \\
5 & 500 & 230 \\
6 & 800 & 163 \\
7 & 1500 & 182 \\
8 & 520 & 180 \\
9 & 750 & 260 \\
10 & 350 & 185 \\
11 & 400 & Flat* \\
12 & 350 & 212 \\
13 & 400 & 150 \\
\hline
\end{tabular}

* Patient on thioridazine

Ocular Tension.-This was measured in the first 150 cases and was less than $22 \mathrm{~mm}$. $\mathrm{Hg}$ (Schiötz) in all of them. Applanation tonometry was carried out in some twenty of the more severely affected cases and readings corresponded to the Schiötz readings using the 5.5 and $10 \mathrm{~g}$. weights. Gonioscopy in three of the most severely affected cases showed a normal open angle with no accumulation of pigment.

Dosage.-The relationship between dosage and incidence of ocular effects is not as marked as in deLong's series, but there is some indication that patients who have had a larger amount of the drug are more likely to be affected. It appears that some subjects are more resistant than others, for several patients were seen who were receiving fairly large doses but showed no sign of ocular deposits.

Duration of Treatment.-Most patients in whom ocular changes were found had received chlorpromazine for several years, but one showed slight lens changes after less than one year's treatment. To the best of our knowledge, this patient had not received the drug previously.

It must be stressed that in some cases it was very difficult to obtain an accurate estimate of how much chlorpromazine had been taken. Many patients had been treated in more than one mental hospital and also by their general practitioners. The amounts recorded in the Tables represent the minimum dose that could have been received.

TABLE III

\begin{tabular}{c||c|c|c}
\hline \multirow{2}{*}{ Sex } & \multirow{2}{*}{$\begin{array}{c}\text { No. of } \\
\text { Cases }\end{array}$} & \multicolumn{2}{c}{ Cases Affected } \\
\cline { 3 - 4 } & Seen & No. & Per cent. \\
\hline Male & 316 & 114 & 36 \\
Female & 146 & 43 & 29 \\
\hline
\end{tabular}

Sex Ratio.-The patients described by Greiner and others (1964) were all female, and he wondered if there were a hormonal factor. However, in this series the incidence of ocular changes was similar in both sexes (Table III).

Laboratory Investigations.-Catecholamine estimations showed no abnormality. Liver function tests were occasionally depressed, consistent with the chlorpromazine therapy.

\section{Discussion}

It appears from this investigation that many patients treated with chlorpromazine for long periods show characteristic lens and corneal changes. No changes of this 
type were seen in a control series of schizophrenic patients not receiving chlorpromazine. These changes did not appear to have any marked effect on visual function, and so far retinal dysfunction has been described by only one author in patients receiving very large doses of the drug.

Because of the site of the lesions in the anterior part of the lens and the back of the cornea there is, as deLong suggests, a strong implication that either the drug, or some metabolite present in the anterior chamber, is responsible for the ocular signs. Photosensitivity may also play a contributory part.

The majority of the affected cases have received more than $300 \mathrm{~g}$. of the drug over a long period and it appears that the changes follow long-term rather than shortterm treatment. In view of the highly beneficial effect of the drug on a large number of very disturbed patients, it is important to decide in a particular case whether it should be discontinued or used in reduced dosage with or without other psychocorrective agents.

In an attempt to clarify the situation, two investigations have been started:

(1) Several patients, including the ones with skin involvement, have been taken off all phenothiazine derivatives. They will be reviewed after one year, together with those in whom treatment is being continued as before.

(2) An attempt is being made actively to reverse the ocular changes by the administration of D-penicillamine - amino mercapto isovaleric acid-an amine which is a fundamental part of the penicillin molecule. Penicillamine is an oral chelating agent and has been used in the treatment of Wilson's disease, certain metal intoxications, and cystinuria.

A chelating agent is a compound which, in addition to forming ordinary covalent or ionic bonds with heavy metals, is able to form a second co-ordinate bond with them through another reactive centre so placed that the end-result is a new and stable ring.

Melanin contains copper and at least two other heavy metals. Tyrosinase, an enzyme involved in the synthesis of melanin, also contains copper. It is hoped that D-penicillamine will bind the copper ions required for tyrosinase action and later remove some of the existing pigmentation.

No cases of completely reversed ocular changes have yet been reported, and because of the limited blood supply to the cornea and lens, it is reasonable to suppose that any change that might occur would be very slow. Greiner and others (1964) have reported encouraging results from the use of penicillamine in an attempt to reverse the skin pigmentation.

The results of this study will be reported subsequently. It will be interesting to see if the lens and ocular changes can be reversed, although such therapy, if effective, will probably be rarely necessary except in the most advanced cases.

\section{Summary}

462 patients in seven mental hospitals in England were examined for eye and skin changes. Of those receiving more than $300 \mathrm{mg}$. chlorpromazine daily for 3 years or more, 36 per cent. showed lens changes and 17 per cent. showed corneal changes. These changes consisted of white and yellowish-white granules, most marked in the axial part of the lens and cornea; they were situated in the anterior capsule and adjoining subcapsular part of the lens, and in the posterior layers of the cornea.

No subjective or objective damage to retinal function could be determined. No 
abnormality in intra-ocular pressure was detected. Except for occasional complaints of slight blurring of vision no subjective ocular symptoms could be elicited.

I should like to thank Prof. E. S. Perkins for his encouragement and advice throughout this survey, Dr. Allan Atkinson for his invaluable help in collecting the patients and helping to organize this investigation, and May and Baker Ltd. for financing the project.

I am grateful to Miss Trotman for her excellent drawings, to Miss J. Behrman for doing the electrooculograms, and to the Medical Superintendents of the hospitals concerned for their co-operation.

\section{REFERENCES}

Ayd, F. J. (1961). J. Amer. med. Ass., 175, 1054.

Ban, T. A., and Lehmann, H. E. (1965). Canad. psychiat. Ass. J., 10, 112.

Barsa, J. A., Newton, J. C., and Saunders, J. C. (1965). J. Amer. med. Ass., 193, 10.

Bock, R., and Swain, J. (1963). Amer. J. Ophthal., 56, 808.

Cairns, R. J., Capoore, H. S., and Gregory, I. D. R. (1965). L Lancet, 1, 239.

Cloud, T. M., HAKim, R., and Griffin, A. C. (1961). Arch. Ophthal. (Chicago), 66, 689.

Delong, S., Poley, B. J., and McFarlane, J. R. (1965). Ibid., 73, 611.

Feldman, P. E., and Frierson, B. D. (1964). Amer. J. Psychiat., 121, 187.

Giacobini, E., and Lassenius, B. (1954). Nord. Med., 52, 1693.

Greiner, A. C., and Berry, K. (1964). Canad. med. Ass. J., 90, 663. , Nicolson, G. A., and BAKer, R. A. (1964). Ibid., 91, 636.

Jonas, S. (1959). Amer. J. Psychiat., 115, 817.

KinRoss-Wright, V. (1956). In "An Evaluation of the Newer Psychopharmacologic Agents and Their Role in Current Psychiatric Practice". Psychiat. Res. Rep. Amer. psychiat. Ass., 4, 89.

MARGERIE, J. DE (1962). Trans. Canad. ophthal. Soc., 25, 160.

MAthalone, M. B. R. (1965). Lancet, 2, 111.

May, R. H., Selymes, P., Weekley, R. D., and Potts, A. M. (1960). J. nerv. ment. Dis., 130, 230.

PotTs, A. M. (1962a). Invest. Ophthal., 1, 522. (1962b). Trans. Amer. ophthal. Soc., 60, 517.

Scott, G. T., and NAding, L. K. (1961). Proc. Soc. exp. Biol. (N.Y.), 106, 88.

Siddall, J. R. (1965). Arch. Ophthal. (Chicago), 74, 460.

SinhA, G. B., and Mitra, S. K. (1955). J. Indian med. Ass., 24, 557.

VERREY, F. (1956). Ophthalmologica (Basel), 131, 296.

Wetterholm, D. H., SNow, H. L., and Winter, F. C. (1965). Arch. Ophthal. (Chicago), 74, 55.

Zelickson, A. S., and Zeller, H. C. (1964). J. Amer. med. Ass., 188, 394. 